\title{
Modern alternative or first-line treatment: How to safely use Negative Pressure Wound Therapy in Diabetic Foot Syndrome?
}

\author{
Beata Mrozikiewicz- Rakowska, M.D., Ph.D., Ewelina Bucior, Joanna Kania, Adriana Nowak, Marek \\ Chojnowski, M.D., Janusz Krzymień, M.D., Ph.D.
}

\begin{abstract}
Clinical experience and basic science studies show that Negative Pressure Wound Therapy (NPWT) is a promising yet still under-used treatment method for patients with diabetic foot syndrome. Despite its advantages, it may carry the risk of serious side effects if the indications and contraindications are not strictly observed. The aim of this article is to discuss myths and facts about NPWT in conditions such as: inadequate blood supply, insufficient wound debridement, osteomyelitis or the necessity to monitor laboratory parameters during the therapy. We will try to define the optimal conditions for NPWT in order to obtain better results and eliminate the risk of side effects.
\end{abstract}

Keywords-negative pressure wound therapy - vacuum therapy - diabetic foot syndrome - diabetic ulcer

\section{INTRODUCTION}

D IABETIC foot syndrome (DFS) is a growing concern of modern medicine. It affects approximately $10-15 \%$ of patients with type 2 diabetes (DM). This number is consistently growing due to aging population and decreasing age of DM onset ${ }^{[1}$ Chronicity and natural predisposition to wound infection in DFS determine the need for optimization of the healing process. NPWT is effective in restoring moisture balance in wound bed, improving blood supply to damaged tissues and eliminating the source of infection. It promotes formation of granulation tissue and finally accelerates wound closure. ${ }^{[2}$ DFS can be the cause of generalized infection and even death of the patient. The most common life threatening complication is amputation. 5-year mortality rate after first amputation is approx. $40 \%$, which is similar to e.g. kidney cancer mortality rate 3

\section{HOW DO THE GUIDELINES PRIORITIZE NPWT IN THE TREATMENT OF DFS?}

Standardized indications for NPWT in the DFS were published recently in 2011 by NPWT-Expert Panel. They define two main goals of DFS patients' treatment.$^{5}$ The primary aim is the wound closure. Of all indications, the strongest recommendation is given to NPWT as a second-line treatment of non-healing wounds and managing surgical wounds of 2 nd

Manuscript received 12.2014; revised 03.2015.

Author affiliations: Department of Gastroenterology and Metabolic Diseases, Medical University of Warsaw, (BMR, EB, JK, AN, JK); Department of Nuclear Medicine, Medical University of Warsaw, (MC)

*Correspondence to: Beata Mrozikiewicz-Rakowska (email: rakowskab123@gmail.com). and 3rd grade in Texas Scale ${ }^{\sqrt{6}}$ in DFS without ischemia. The secondary goal is stopping the wound progression (degree of recommendation (B)). The guidelines emphasize the importance of NPWT as a method that fulfils the task of preventing the amputation and re-amputation of the limb and has indirect influence on mortality of patients after amputations. It should be considered in every patient with DFS. Before the treatment, however, one should carefully analyse all the contraindications and answer some key questions about the patient. These issues will be discussed below.

\section{A. Can NPWT be used in patients with neuroischemic DFS?}

NPWT increases levels of TGF- $\beta$ and PDGF, accelerates the formation of granulation tissue and amplifies angiogenesis. ${ }^{7]}$ Xia observed an increase of VEGF, EGF, PDGF and angiotensin-2 concentration and reduction of fibroblast growth factor level ${ }^{[}$Furthermore, NPWT mechanically contributes to optimize the perfusion at negative pressure of $-125 \mathrm{mmHg}$. According to Timmers, the hypoperfusion occurs only at a negative pressure below $-500 \mathrm{mmHg} 9$ Kasai draws the hypothesis that the suction pressure contributes to the occlusion of the majority of the capillary vessels located on the edge of the wound ${ }^{10}$ Present studies show that even negative pressure of $-125 \mathrm{mmHg}$ will produce a zone of increased perfusion $(2.5 \mathrm{~cm})$ as well as ischemic zone within and immediately around $(0.5 \mathrm{~cm})$ the edges of the wound. Temporary ischemia can promote healing through HIF production ${ }^{11}$ Borgquist demonstrates that using lower levels of negative pressure of $-80 \mathrm{mmHg}$ does not have influence on the therapeutic effect.12 In patients with impaired blood flow in the lower limb arteries optimal negative pressure levels can cause the necrosis in the wound edges 13 14 14 This is because patients with an ABI of less than 0.6 should not be considered for the NPWT. The $\mathrm{TpO} 2$ measurement should be diagnostic method of choice, but it is not widely available. Levels below $30 \mathrm{mmHg}$ limit the use of NPWT. Every patient with clinically significant arterial occlusions should first undergo revascularization procedures.

\section{B. Can we substitute debridement by NPWT?}

The proper wound treatment requires a comprehensive approach. The guidelines for wound management were published in 2002 by European Wound Management Association (EWMA). According to the TIME concept comprehensive care 
of wound bed consists of: tissue management, control of infection and inflammation, moisture balance and advancement of the epithelial edge of the wound ${ }^{[15}$ NPWT fits perfectly into the above-mentioned strategy, which is extremely important in the treatment of DFS ulceration. It should be noted, that proper preparation and debridement of the wound is essential before the treatment. Removal of necrotic tissue and bacterial burden helps to define the size and condition of the wound. We emphasize that in neuropathic ulcers the superficial, hyperkeratotic layer can cover the infected tissues. Deep debridement can reveal bare bone fragments, thus limiting the use of traditional NPWT systems. Minimization of the infection potential and prolonged inflammatory process induced by pro-inflammatory factors from necrotic tissue contributes to the optimization of the treatment conditions. To sum up, NPWT is in keeping with the TIME concept, provided that the deep debridement before the treatment is achieved.

\section{How does NPWT system control the presence of infection signs in the wound?}

The amount of exudate in chronic wounds is increased and leads to maceration of surrounding tissues. The composition of the fluid is also imbalanced, with increased level of proinflammatory factors. Chronic inflammation in the wound bed is expressed through the high levels of TNF- $\alpha$, IL- $1 \beta$ and IL-6 in the exudate! $!^{[1-18]}$ It is proven that an increase in the level of Il-1 and a reduction of TGF- $\beta$ induces higher expression of metalloproteinases (MMP). The levels of MMP are increased in diabetic ulcers. Many researchers have observed a significant prevalence of MMP-9 and MMP-2, 19, The healing and remodelling processes can be inhibited by inadequate ratio of metalloproteinases to their tissue inhibitors (TIMP) $\underline{22}$ Hyperglycaemia, often accompanying diabetic foot ulcers, is conductive to further development of inflammation through the activation of mitogen-activated protein kinase and protein kinase $\mathrm{C}$, as well as oxidative stress and AGEs ${ }^{23}$ Removal of excess volume of exudate and MMP in NPWT is likely to increase healing rate and tissue regeneration. 24

The additional benefit in wounds associated with abundant exudate is the physical decompression of the pressure on the wound bed. According to Young, in 4 days of NPWT swelling was decreased by $43 \%$. This can be explained by macrodeformation of the tissues, leading to reverse tissue expansion and also altering the blood flow in the wound vessels. ${ }^{[25}$ Numerous studies show that the addition of exudate from chronic wounds to the cell culture inhibits the proliferation of the cells. 18 26 27

Mechanical suction in NPWT reduces swelling and also allows controlling the infection by decreasing number of microorganisms and dead cells, which can cause prolonged inflammation and lack of wound healing.

NPWT is indicated especially in wounds involving extensive exudate that is difficult to manage. "Dry wounds" (the amount of aspirate $20-50 \mathrm{ml} /$ day) require special care and considering a method other than NPWT.

\section{Does the exudate removal reduce the amount of infectious agent in the wound?}

A clinical infection in the wound bed and adjacent tissues is a major problem leading to persistent inflammation and significantly delayed healing process. Undoubtedly, improving blood circulation and function of inflammatory cells in NPWT contributes to the proper management of infected wounds. This is why patients with grade I and II in PEDIS scale can benefit most from using NPWT. According to the research by Moues and Weed, in animal model of chronic wounds, the number of bacterial colonies has not diminished during NPWT, 28,29 the bacterial profile, however, has changed from anaerobic to aerobic G+ species. According to studies, S. aureus is the dominating microorganism in ulcers treated with vacuum therapy ${ }^{[29}$ It appears that the colonization by $S$. aureus may have positive effect on the wound healing. ${ }^{30]}$ There is discussion on the possible negative effect of foams used in NPWT and their role in spreading the infection, which may result from the problem of foam contamination. ${ }^{32}$ NPWT-EP recommends repetitive changes of the NPWT dressings every 2 or 3 days. Special attention should be given to signs of infection and fibres of dressing left in the wound. Foam or gauze dressings can be used. According to recent publications, both types of dressing are equally effective at delivering negative pressure, wound contraction and stimulation of blood flow at the wound edge. The advantage of gauze is its fast application and easy adjustment to the surface of wounds. In contrast to foam dressing, application of gauze may be quite challenging in case of a complex wound with several layers and uneven bed 33 However, studies have documented an in-growth of granulation tissue into the cells of the open cell polyurethane foam. This may cause patients to experience pain during dressing changes and a disturbance of the re-epithelialisation process. 34 .37

Proper wound healing by granulation may be inhibited by the remaining fibres of the dressing. Using wound contact layers helps eliminate in-growth and pain. 38 The NPWT method is based on the induction of negative pressure in purified wounds and it is natural that after discontinuation of drainage the production of exudate may be increased. The sponge used in NPWT should be prepared with special attention in order to avoid covering healthy skin with the dressing. Too large a sponge may damage healthy skin around the wound and increase the risk of wet necrosis or fistula formation. Local allergic reactions were also observed in NPWT patients, manifesting as pruritus or contact eczema (e.g. contact dermatitis caused by the film covering the sponge). It is only rarely that the therapy has to be discontinued, especially in cases of uncontrolled bleeding or a blood clot formation under the dressing.

\section{E. Is osteomyelitis a contraindication for NPWT in DFS?}

The development of inflammation and infection during the NPWT may be overlooked. Anatomy of the foot allows rapid spread of infection along the muscles and tendons. ${ }^{39}$ Special attention should be given to osteomyelitis, which requires chronic anti-microbial therapy or surgical resection. The risk of osteomyelitis increases when the ulcer is not healing after 
six weeks of proper therapy. Clinically, osteomyelitis can be confirmed in case of a deep, extensive ulceration when the bone is visible at the bottom of the wound bed or when the PTBT test is positive. The local ischemia caused by NPWT could increase the area of infection when osteomyelitis is present. In case of extensive infections (defined as grade 3 and 4 on a PEDIS scale), standard NPWT systems should not be used. Before the NPWT, osteomyelitis needs to be ruled out in order to prevent bacterial translocation from the wound bed to bone ${ }^{40}$ In patients with osteomyelitis NPWT should not be initiated until the appropriate antibiotic therapy and the wound debridement have been performed, including removal of infected bone if necessary ${ }^{41}$

\section{F. What laboratory parameters should be monitored during NPWT?}

Chronic wounds are conducive to developing anaemia. Patients with DFS are extremely prone to ischemia. Physicians should take care that the levels of haemoglobin stay optimal and not fall below $10 \mathrm{~g} / \mathrm{dl}$. Emphasis on this parameter reduces the likelihood of ischemic episodes and allows the wound to heal properly. Patients on chronic anticoagulant therapy as well as patients with active bleeding in medical history or bleeding disorders require increased attention due to the bleeding risk. However, the use of anticoagulants is not a contraindication to NPWT.

\section{G. Does NPWT system induce neoplastic process?}

It should be noted that increased perfusion may be a problem in wounds with neoplastic lesions. To minimize the risk of uninhibited tumour growth, patients with atypical ulcerations and malignancies in other organs should be screened for the presence of neoplastic cells in wound bed before the NPWT treatment. 42

\section{CONCLUSIONS}

NPWT reduces the number of required dressing changes and allows the patient to rest. ${ }^{43}$ Fewer interventions in the wound decrease the likelihood of contamination. ${ }^{44}$ Moreover, the change of dressing used in vacuum therapy is less painful for patients. At the beginning of the therapy, however, patients could feel pain or discomfort due to the negative pressure. The vacuum stimulates growth of new tissue and epithelialization. It contributes to the well-being of the patient, since the first results are soon visible ${ }^{45}$ In addition, negative pressure continuously removes the excess of exudate, which reduces odour from the wound ${ }^{46}$ However, NPWT must be applied for at least 22 hours a day to yield such results.

NPWT enables the concomitant rehabilitation, which shortens the period of treatment.

So far, NPWT was considered an expensive technical novelty but it has a significant advantage in terms of relative costeffectiveness in comparison with conventional therapy. Care for patients with active ulcer multiplies the expenses incurred by the health care system (5.4 times compared to patients with isolated DM) $\stackrel{48}{ }$ Wound closure reduces the amount of spending for proper wound management. It should be noted that the treatment of superficial infection is approx. 11 times cheaper than in the case of generalized infection which often results in the need for amputation. Reduced frequency of dressing changes, faster wound healing and the possibility of mobilization of patients in the same time, lowers the cost of vacuum treatment compared to standard therapy $[49$

Growing knowledge on mechanism of action of standard NPWT increases safety of this therapy in patients with DFS. The best results of NPWT are observed in patients with DFS in grade 2nd and 3rd in Texas Scale. Ischemic wounds before revascularization are a contraindication for this therapy. To stop the infection from spreading, it is recommended to change foam and gauze every 2-3 days. Special care is advised while changing dressings to avoid in-grows of granulation tissue into the dressing. Monitoring of morphology parameters is indicated before and during the therapy. When lengthy healing is observed, histopathological assessment is advised to exclude malignancy. A comprehensive treatment of the patient involving both standard methods and NPWT significantly increases the chances of saving the affected limb.

\section{REFERENCES}

[1] N. Singh, "Preventing foot ulcers in patients with diabetes," JAMA, vol. 293, no. 2, p. 217 2005. http://dx.doi.org/10.1001/jama.293.2.217

[2] R. Garg, K. Bajaj, S. Garg, P. Nain, and S. Uppal, "Role of negative pressure wound therapy in healing of diabetic foot ulcers," Journal of Surgical Technique and Case Report, vol. 3, no. 1, p. 172011. http://dx.doi.org/10.4103/2006-8808.78466

[3] P. Krasnodebski, A. Zoń, B. Mrozikiewicz-Rakowska, and W. Karnafel, "Ryzyko amputacji i umieralność osób z zaawansowanym zespołem stopy cukrzycowej - badanie obserwacyjne," Medycyna Metaboliczna, vol. 17, no. 4, pp. 29-33 2013.

[4] R. T. Greenlee, T. Murray, S. Bolden, and P. A. Wingo, "Cancer statistics, 2000," CA: A Cancer Journal for Clinicians, vol. 50, no. 1, pp. 7-33 2000. http://dx.doi.org/10.3322/canjclin.50.1.7

[5] S. Vig, C. Dowsett, L. Berg, C. Caravaggi, P. Rome, H. Birke-Sorensen, A. Bruhin, M. Chariker, M. Depoorter, R. Dunn, F. Duteille, F. Ferreira, J. F. Martínez, G. Grudzien, D. Hudson, S. Ichioka, R. Ingemansson, S. Jeffery, E. Krug, C. Lee, M. Malmsjo, N. Runkel, R. Martin, and J. Smith, "Evidence-based recommendations for the use of negative pressure wound therapy in chronic wounds: Steps towards an international consensus," Journal of Tissue Viability, vol. 20, pp. S1-S18 2011. http://dx.doi.org/10.1016/j.jtv.2011.07.002

[6] S. O. Oyibo, E. B. Jude, I. Tarawneh, H. C. Nguyen, L. B. Harkless, and A. J. Boulton, "A comparison of two diabetic foot ulcer classification systems: The wagner and the university of texas wound classification systems," Diabetes Care, vol. 24, no. 1, pp. 84-88 2001. http://dx.doi.org/10.2337/diacare.24.1.84

[7] A. K. McNulty, M. Schmidt, T. Feeley, P. Villanueva, and K. Kieswetter, "Effects of negative pressure wound therapy on cellular energetics in fibroblasts grown in a provisional wound (fibrin) matrix," Wound Repair and Regeneration, vol. 17, no. 2, pp. 192-199 2009. http://dx.doi.org/10.1111/j.1524-475X.2009.00460.x

[8] C. Xia, A. Yu, B. Qi, M. Zhou, Z. Li, and W. Wang, "Analysis of blood flow and local expression of angiogenesis-associated growth factors in infected wounds treated with negative pressure wound therapy," Molecular Medicine Reports 2014. http://dx.doi.org/10.3892/mmr.2014. 1997

[9] M. S. Timmers, S. L. Cessie, P. Banwell, and G. N. Jukema, "The effects of varying degrees of pressure delivered by negative-pressure wound therapy on skin perfusion," Annals of Plastic Surgery, vol. 55, no. 6, pp. 665-671 2005. http://dx.doi.org/10.1097/01.sap.0000187182.90907.3d

[10] Y. Kasai, H. Nemoto, N. Kimura, Y. Ito, and N. Sumiya, "Application of low-pressure negative pressure wound therapy to ischaemic wounds," Journal of Plastic, Reconstructive \& Aesthetic Surgery, vol. 65, no. 3, pp. 395-398 2012. http://dx.doi.org/10.1016/j.bjps.2011.08.010 
[11] O. Borgquist, E. Anesäter, E. Hedström, C. K. Lee, R. Ingemansson, and M. Malmsjö, "Measurements of wound edge microvascular blood flow during negative pressure wound therapy using thermodiffusion and transcutaneous and invasive laser doppler velocimetry," Wound Repair Regen, vol. 19, no. 6, pp. 727-733 2011. http://dx.doi.org/10.1111/j. 1524-475X.2011.00741.X

[12] O. Borgquist, R. Ingemansson, and M. Malmsjö, "The influence of low and high pressure levels during negative-pressure wound therapy on wound contraction and fluid evacuation," Plastic and Reconstructive Surgery, vol. 127, no. 2, pp. 551-559 2011. http: //dx.doi.org/10.1097/PRS.0b013e3181fed52a

[13] M. L. Venturi, C. E. Attinger, A. N. Mesbahi, C. L. Hess, and K. S. Graw, "Mechanisms and clinical applications of the vacuum-assisted closure (VAC) device," American Journal of Clinical Dermatology, vol. 6, no. 3, pp. 185-194 2005. http://dx.doi.org/10. 2165/00128071-200506030-00005

[14] C. E. Attinger, J. E. Janis, J. Steinberg, J. Schwartz, A. Al-Attar, and K. Couch, "Clinical approach to wounds: D??bridement and wound bed preparation including the use of dressings and wound-healing adjuvants," Plastic and Reconstructive Surgery, vol. 117, no. SUPPLEMENT, pp. 72S-109S 2006. http://dx.doi.org/10.1097/01.prs.0000225470.42514.8f

[15] G. S. Schultz, R. G. Sibbald, V. Falanga, E. A. Ayello, C. Dowsett, K. Harding, M. Romanelli, M. C. Stacey, L. Teot, and W. Vanscheidt, "Wound bed preparation: a systematic approach to wound management," Wound Repair Regen, vol. 11, no. s1, pp. S1-S28 2003. http: //dx.doi.org/10.1046/j.1524-475X.11.s2.1.x

[16] B. S. Pukstad, L. Ryan, T. H. Flo, J. Stenvik, R. Moseley, K. Harding, D. W. Thomas, and T. Espevik, "Non-healing is associated with persistent stimulation of the innate immune response in chronic venous leg ulcers," Journal of Dermatological Science, vol. 59, no. 2, pp. 115-122 2010. http://dx.doi.org/10.1016/j.jdermsci.2010.05.003

[17] H. J. Wallace and M. C. Stacey, "Levels of tumor necrosis factor- $\alpha$ $(\mathrm{TNF}-\alpha)$ and soluble TNF receptors in chronic venous leg ulcers correlations to healing status," J Investig Dermatol, vol. 110, no. 3, pp 292-296 1998. http://dx.doi.org/10.1046/j.1523-1747.1998.00113.x

[18] N. J. Trengove, H. Bielefeldt-Ohmann, and M. C. Stacey, "Mitogenic activity and cytokine levels in non-healing and healing chronic leg ulcers," Wound Repair and Regeneration, vol. 8, no. 1, pp. 13-25 2000. http://dx.doi.org/10.1046/j.1524-475x.2000.00013.x

[19] S. K. Beidler, C. D. Douillet, D. F. Berndt, B. A. Keagy, P. B. Rich, and W. A. Marston, "Multiplexed analysis of matrix metalloproteinases in leg ulcer tissue of patients with chronic venous insufficiency before and after compression therapy," Wound Repair and Regeneration, vol. 16, no. 5, pp. 642-648 2008. http://dx.doi.org/10.1111/j.1524-475X.2008.00415.x

[20] D. R. Yager, L.-Y. Zhang, H.-X. Liang, R. F. Diegelmann, and I. K. Cohen, "Wound fluids from human pressure ulcers contain elevated matrix metalloproteinase levels and activity compared to surgica wound fluids." J Invest Dermatol, vol. 107, no. 5, pp. 743-748 1996. http://dx.doi.org/10.1111/1523-1747.ep12365637

[21] R. Lobmann, A. Ambrosch, G. Schultz, K. Waldmann, S. Schiweck, and H. Lehnert, "Expression of matrix-metalloproteinases and their inhibitors in the wounds of diabetic and non-diabetic patients," Diabetologia, vol. 45, no. 7, pp. 1011-1016 2002. http://dx.doi.org/10. 1007/s00125-002-0868-8

[22] B. Mwaura, B. Mahendran, N. Hynes, D. Defreitas, G. Avalos, T. Adegbola, M. Adham, C. Connolly, and S. Sultan, "The impact of differential expression of extracellular matrix metalloproteinase inducer matrix metalloproteinase-2, tissue inhibitor of matrix metalloproteinase2 and PDGF-AA on the chronicity of venous leg ulcers," European Journal of Vascular and Endovascular Surgery, vol. 31, no. 3, pp. 306-310 2006. http://dx.doi.org/10.1016/j.ejvs.2005.08.007

[23] S. McLennan, D. Min, and D. Yue, "Matrix metalloproteinases and their roles in poor wound healing in diabetes," Wound Practice and Research, vol. 16, pp. 116-121 2008

[24] S. Mendez-Eastman, "Guidelines for using negative pressure wound therapy," Advances in Skin \& Wound Care, vol. 14, no. 6, pp. 314-323 2001. http://dx.doi.org/10.1097/00129334-200111000-00015

[25] S. R. Young, S. Hampton, and R. Martin, "Non-invasive assessment of negative pressure wound therapy using high frequency diagnostic ultrasound: oedema reduction and new tissue accumulation,' International Wound Journal, vol. 10, no. 4, pp. 383-388 2012 http://dx.doi.org/10.1111/j.1742-481X.2012.00994.x

[26] B. Bucalo, W. H. Eaglstein, and V. Falanga, "Inhibition of cell proliferation by chronic wound fluid," Wound Repair Regen, vol. 1, no. 3 pp. 181-186 1993. http://dx.doi.org/10.1046/j.1524-475X.1993.10308.x
[27] T. Phillips, H. al Amoudi, M. Leverkus, and H. Park, "Effect of chronic wound fluid on fibroblasts," J Wound Care, vol. 7, p. 527-532 1998.

[28] T. Weed, C. Ratliff, and D. B. Drake, "Quantifying bacterial bioburden during negative pressure wound therapy," Annals of Plastic Surgery, vol. 52, no. 3, pp. 276-279 2004. http://dx.doi.org/10.1097/01.sap. $0000111861.75927 .4 \mathrm{~d}$

[29] C. M. Mouës, M. C. Vos, G.-J. C. V. D. Bemd, T. Stijnen, and S. E. Hovius, "Bacterial load in relation to vacuum-assisted closure wound therapy: A prospective randomized trial," Wound Repair and Regeneration, vol. 12, no. 1, pp. 11-17 2004. http: //dx.doi.org/10.1111/j.1067-1927.2004.12105.x

[30] M. Laato, J. Niinikoski, C. Lundberg, and B. Gerdin, "Inflammatory reaction and blood flow in experimental wounds inoculated with staphylococcus aureus," European Surgical Research, vol. 20, no. 1, pp. 33-38 1988. http://dx.doi.org/10.1159/000128738

[31] S. M. Levenson, "Wound healing accelerated by staphylococcus aureus," Arch Surg, vol. 118, no. 3, p. 310 1983. http://dx.doi.org/10. 1001/archsurg.1983.01390030042007

[32] E. Yusuf, X. Jordan, M. Clauss, O. Borens, M. Mäder, and A. Trampuz, "High bacterial load in negative pressure wound therapy (NPWT) foams used in the treatment of chronic wounds," Wound Repair Regen, vol. 21, no. 5, pp. 677-681 2013. http://dx.doi.org/10.1111/wrr.12088

[33] S. Jeffrey, "Advanced wound therapies in the management of severe military lower limb trauma: a new perspective," Eplasty, vol. 9, p. e28 2009.

[34] P. E. Campbell, G. S. Smith, and J. M. Smith, "Retrospective clinical evaluation of gauze-based negative pressure wound therapy," International Wound Journal, vol. 5, no. 2, pp. 280-286 2008. http://dx.doi.org/10.1111/j.1742-481X.2008.00485.x

[35] M. Kaufman and D. Pahl, "Vacuum-assisted closure therapy: wound care and nursing implications," Dermatol Nurse, vol. 4, pp. 317-25 2003.

[36] J. Bickels, Y. Kollender, J. C. Wittig, N. Cohen, I. Meller, and M. M. Malawer, "Vacuum-assisted wound closure after resection of musculoskeletal tumors," Clinical Orthopaedics and Related Research, vol. 441, pp. 346-350 2005. http://dx.doi.org/10.1097/01.blo. $0000180450.21350 .3 \mathrm{e}$

[37] M. Shirakawa and R. R. Isseroff, "Topical negative pressure devices," Arch Dermatol, vol. 141, no. 11 2005. http://dx.doi.org/10.1001/ archderm.141.11.1449

[38] P. Stanirowski and W. Sawicki, "Nowoczesne metody terapii trudno gojacych sie położniczo- ginekologicznych ran pooperacyjnych- analiza przydatności i skuteczności stosowania," Postepy Nauk Medycznych, vol. 7, pp. 475-487 2013.

[39] J. Apelqvist, K. Bakker, W. H. van Houtum, and N. C. Schaper, "Practical guidelines on the management and prevention of the diabetic foot," Diabetes Metab. Res. Rev., vol. 24, no. S1, pp. S181-S187 2008. http://dx.doi.org/10.1002/dmrr.848

[40] S. McCallon, C. Knight, J. Valiulus, M. Cunningham, J. McCulloch, and L. Farinas, "Vacuum-assisted closure versus saline-moistened gauze in the healing of postoperative diabetic foot wounds," vol. 46, no. 8, pp. 28-32 2000.

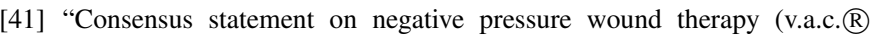
therapy) for themanagement of diabetic foot wounds," Ostomy Wound Management, vol. Suppl, pp. 1-32 2006.

[42] M. Yuan-Innes, C. Temple, and M. Lacey, "Vacuum-assisted wound closure: a new approach to spinal wounds with exposed hardware," Spine(Phila Pa 1976), vol. 26, no. 3, pp. E3-E4 2001.

[43] C. Mouës, G.-J. van den Bemd, W. Meerding, and S. Hovius, "An economic evaluation of the use of TNP on full-thicknes wounds," J Wound Care, vol. 14, no. 5, pp. 224-227 2005. http://dx.doi.org/10.12968/jowc.2005.14.5.26776

[44] B. E. Leininger, T. E. Rasmussen, D. L. Smith, D. H. Jenkins, and C. Coppola, "Experience with wound VAC and delayed primary closure of contaminated soft tissue injuries in iraq," The Journal of Trauma: Injury, Infection, and Critical Care, vol. 61, no. 5, pp. 1207-1211 2006. http://dx.doi.org/10.1097/01.ta.0000241150.15342.da

[45] D. G. Armstrong and L. A. Lavery, "Negative pressure wound therapy after partial diabetic foot amputation: a multicentre, randomised controlled trial," The Lancet, vol. 366, no. 9498, pp. 1704-1710 2005. http://dx.doi.org/10.1016/S0140-6736(05)67695-7

[46] T. Hurd, P. Chadwick, J. Cote, J. Cockwill, T. R. Mole, and J. M. Smith, "Impact of gauze-based NPWT on the patient and nursing experience in the treatment of challenging wounds," International Wound Journal, vol. 7, no. 6, pp. 448-455 2010. http://dx.doi.org/10.1111/j.1742-481X.2010.00714.x

[47] C. A. Park, A. J. Defranzo, M. W. Marks, and J. A. Molnar, "Outpatient reconstruction using integra ${ }^{\mathrm{TM}}$ and subatmospheric pressure," Annals 
of Plastic Surgery, vol. 62, no. 2, pp. 164-169 2009. http: //dx.doi.org/10.1097/SAP.0b013e31817d87cb

[48] S. D. Ramsey, K. Newton, D. Blough, D. K. McCulloch, N. Sandhu, G. E. Reiber, and E. H. Wagner, "Incidence, outcomes, and cost of foot ulcers in patients with diabetes," Diabetes Care, vol. 22, no. 3, pp. 382-387 1999. http://dx.doi.org/10.2337/diacare.22.3.382

[49] J. Apelqvist, D. G. Armstrong, L. A. Lavery, and A. J. Boulton, "Resource utilization and economic costs of care based on a randomized trial of vacuum-assisted closure therapy in the treatment of diabetic foot wounds," The American Journal of Surgery, vol. 195, no. 6, pp. 782-788 2008. http://dx.doi.org/10.1016/j.amjsurg.2007.06.023 